\title{
High free thyroxine levels are associated with QTc prolongation in males
}

\author{
Charlotte van Noord ${ }^{1,5}$, Wendy M van der Deure ${ }^{2}$, Miriam C J M Sturkenboom ${ }^{1,3}$, Sabine M J M Straus ${ }^{1,5}$, \\ Albert Hofman ${ }^{1}$, Theo J Visser ${ }^{2}$, Jan A Kors ${ }^{3}$, Jacqueline C M Witteman ${ }^{1}$ and Bruno H Ch Stricker ${ }^{1,2,4}$ \\ Departments of ${ }^{1}$ Epidemiology and Biostatistics, ${ }^{2}$ Internal Medicine and ${ }^{3}$ Medical Informatics, Erasmus Medical Center, PO Box 2040,3000 CA Rotterdam, \\ The Netherlands \\ ${ }^{4}$ The Inspectorate for Health Care, PO Box 16119, 2500 BC, The Hague, The Netherlands \\ ${ }^{5}$ The Dutch Medicines Evaluation Board, PO Box 16229, 2500 BE, The Hague, The Netherlands \\ (Correspondence should be addressed to B H Ch Stricker at Department of Epidemiology and Biostatistics, Erasmus Medical Center; \\ Email: b.stricker@erasmusmc.nl)
}

\begin{abstract}
The literature on the effect of excess thyroid hormone on ventricular repolarization is controversial. To study whether free thyroxine $\left(\mathrm{T}_{4}\right)$ and $\mathrm{TSH}$ are associated with QTc prolongation we conducted population-based cohort study. This study was conducted as part of the Rotterdam Study and included 365 men and 574 women aged 55 years and older with an electrocardiogram, who were randomly sampled for the assessment of thyroid status (free $\mathrm{T}_{4} / \mathrm{TSH}$ ) at baseline, after exclusion of participants with hypothyroidism, use of antithyroid drugs, thyroid hormones or digoxin, left ventricular hypertrophy, and left and right bundle branch block. Endpoints were the length of the QTc interval and risk of borderline QTc prolongation. The associations were examined by means of linear and logistic regression analysis, adjusted for age and gender, diabetes mellitus, myocardial infarction, hypertension, and heart failure. Overall, there was no significant association between TSH and QTc interval
\end{abstract}

$(0 \cdot 8 \mathrm{~ms}(95 \%$ confidence interval $(\mathrm{CI})-3 \cdot 5,5 \cdot 2)$ in the first quintile compared with the fifth quintile). Subjects in the fifth quintile of free $\mathrm{T}_{4}$ did not have an increased QTc interval (3.2 ms $(95 \% \mathrm{CI}-1 \cdot 1,7 \cdot 6))$; stratification on gender showed an increment of $10.9 \mathrm{~ms}(95 \% \mathrm{CI} 3 \cdot 4,18 \cdot 3)$ in the fifth quintile in men and $1 \cdot 1 \mathrm{~ms}(95 \% \mathrm{CI}-4 \cdot 2,6 \cdot 3)$ in the fifth quintile of free $T_{4}$ in women. When compared with subjects in the first quintile, male subjects in the fifth quintile of free $\mathrm{T}_{4}$ had a significantly increased risk of a borderline QTc interval and QTc prolongation (odds ratio 2.40 (95\% CI 1.20, 4.80)). High levels of free $T_{4}$ are associated with substantial QTc prolongation in men of up to $10 \mathrm{~ms}$. The fact that free $\mathrm{T}_{4}$ is also associated with a significantly increased risk of borderline and prolonged QTc values with its risk of sudden cardiac death, endorses the clinical importance of our findings.

Journal of Endocrinology (2008) 198, 253-260

\section{Introduction}

An excess of thyroid hormone exerts a major effect on the cardiovascular system, and the influence of thyroid disorders on heart rhythm, output, and contractility has been widely studied (Polikar et al. 1993). Relatively little, however, is known about the effect of thyroid hormone on ventricular repolarization. It has been reported that hypothyroidism is associated with prolongation of the heart rate-corrected QT (QTc) interval (Sarma et al. 1990, Fazio et al. 1992), a measure of duration of ventricular repolarization. In hyperthyroidism, the situation is more controversial, since prolonged and shortened QTc intervals both have been reported (Linder 1955, Johnson et al. 1973, Fisher 1982, Sharp et al. 1985, Binah et al. 1987, Gomberg-Maitland \& Frishman 1998, Colzani et al. 2001, Dorr et al. 2006, Owecki et al. 2006). Decreased repolarization times have been reported in several animal studies (Johnson et al. 1973, Sharp et al. 1985, Binah et al. 1987, Gomberg-Maitland \& Frishman 1998) and in one human study (Dorr et al. 2006) and at the same time, QTc prolongation has been reported in patients with hyperthyroidism (Linder 1955, Fisher 1982, Colzani et al. 2001, Owecki et al. 2006). A potential explanation for an association with prolongation of the QTc interval is an increased activity of cardiac $\mathrm{Na}^{+} / \mathrm{K}^{+}$ATPase in thyroid hormone excess, leading to increased intracellular $\mathrm{K}^{+}$with subsequent membrane hyperpolarization and an increase in QTc duration (Polikar et al. 1993, Colzani et al. 2001). A prolonged QTc interval may be clinically relevant, since an increase in ventricular repolarization time may result in early after depolarizations, which in turn may induce re-entry and thereby provoke Torsade de Pointes and fatal ventricular arrhythmias (Lasser et al. 2002, Al-Khatib et al. 2003, Yap \& Camm 2003, Roden 2004, Straus et al. 2006).

Because of these contradictory results and limited data concerning hyperthyroidism and the duration of the QTc 
interval, we studied the association of thyrotropin (TSH) and free thyroxine $\left(\mathrm{T}_{4}\right)$ with the QTc interval in a prospective, population-based study of elderly.

\section{Materials and Methods}

\section{Setting and study design}

The Rotterdam study is a population-based cohort study, which started with a baseline visit between 1990 and 1993 . The Medical Ethics Committee of the Erasmus Medical Center, Rotterdam, the Netherlands, approved the study. All inhabitants of Ommoord, a suburb of Rotterdam, aged 55 years and over, were invited to participate $(n=10275)$. Of them, 7983 (78\%) gave their written informed consent and took part in the baseline examination (Rotterdam Study). Objectives and methods of the Rotterdam Study have been described in detail elsewhere (Hofman et al. 1991, 2007). At baseline, all the participants were visited at home for a standardized questionnaire, and 7151 were subsequently examined at the research center. The cohort is continuously being monitored for major morbidity and mortality through linkage of the Rotterdam Study database with general practitioner and municipality records.

\section{Study population}

Thyroid status was assessed in a random selection of 2000 participants from the Rotterdam Study at baseline, as has been described previously (Kalmijn et al. 2000). After exclusion of subjects for whom no blood was available or who used amiodarone at baseline (due to the effects of this drug on thyroid function) (Harjai \& Licata 1997), TSH was assessed in 1843 participants. Due to technical and logistical reasons, free $\mathrm{T}_{4}$ could only be assessed in 1544 of these participants. Electrocardiograms (ECGs) were available for 1126 of these participants at the time of the first visit.

We excluded participants with clinical hypothyroidism (TSH $>4.3 \mathrm{mU} / 1$ and free $\mathrm{T}_{4}<11 \mathrm{pmol} / \mathrm{l}$ ) or subclinical hypothyroidism $\left(\mathrm{TSH}>4.3 \mathrm{mU} / 1\right.$ and free $\mathrm{T}_{4} \geq 11 \mathrm{pmol} / \mathrm{l}$; $n=72$ ), since hypothyroidism is associated with QTc prolongation (Sarma et al. 1990, Fazio et al. 1992). Furthermore, we excluded participants with ECG evidence of left ventricular hypertrophy $(n=44)$, left and right bundle branch block $(n=17$ and 30 respectively) and/or participants using digoxin $(n=21)$, antithyroid drugs $(n=6)$, and thyroid hormones $(n=11)$, since these conditions can alter the QTc interval (Kulan et al. 1998, Piotrowicz et al. 2007). Consequently, the study population consisted of 939 participants (Fig. 1).

\section{Assessment of thyroid status}

At baseline, non-fasting serum samples were obtained, which were put on ice directly and processed within $30 \mathrm{~min}$ after which they were kept frozen at $-20{ }^{\circ} \mathrm{C}$. TSH levels were measured with TSH Lumitest (Henning, Berlin, Germany; Trantow et al. 1994). The reference range of serum TSH levels was $0 \cdot 4-4 \cdot 3 \mathrm{mU} / \mathrm{l}$. Serum-free $\mathrm{T}_{4}$ was measured by a chemoluminescence assay (Vitros, ECI Immunodiagnostic System, Ortho-Clinical Diagnostics, Amersham, UK), the reference range of serum-free $\mathrm{T}_{4}$ levels was $11-25 \mathrm{pmol} / \mathrm{l}$. Participants with TSH levels lower than $0.4 \mathrm{mU} / 1$ and free $\mathrm{T}_{4}$ levels higher than $25 \mathrm{pmol} / 1$ were considered to have clinical hyperthyroidism, and participants with TSH levels lower than $0.4 \mathrm{mU} / 1$ and free $\mathrm{T}_{4}$ levels between 11 and $25 \mathrm{pmol} / 1$ were considered to have subclinical hyperthyroidism.

\section{QTc prolongation}

A 12-lead resting ECG was recorded with an ACTA electrocardiograph (ESAOTE, Florence, Italy) at a sampling frequency of $500 \mathrm{~Hz}$ and stored digitally. The ECGs and serum samples were obtained on the same day. All ECGs were processed by the modular ECG analysis system (MEANS) to obtain ECG measurements. The MEANS program has been evaluated extensively and has been validated (Willems et al. 1987, 1991, van Bemmel et al. 1990, de Bruyne et al. 1997). In one of these validation studies, ECGs with selected abnormalities were analyzed by 5 cardiologists and 11 different computer programs of which MEANS performed as one of the best (Willems et al. 1987) In another validation study in which QT intervals by manual measurement were compared with those generated by ECG machines, manual and automated measurements generated similar numerical results in three studies in healthy volunteers, which all included a positive control (Darpo et al. 2006). MEANS determines common onsets and offsets for all 12 leads together on one representative averaged beat, with the use of template matching techniques (van Bemmel et al. 1990). The MEANS program determines the QT interval from the start of the QRS complex until the end of the T wave. To adjust for heart rate, Bazett's formula $(\mathrm{QTc}=\mathrm{QT} / \sqrt{\mathrm{R} R})$ was used (Bazett 1920). European regulatory guidelines were used to categorize the QTc interval into three categories: normal, borderline, and prolonged. For men, the cut-off points were $<430 \mathrm{~ms}$ (normal), 430-450 ms (borderline), and $>450 \mathrm{~ms}$ (prolonged), and for women $<450 \mathrm{~ms}$ (normal), 450-470 ms (borderline), and $>470 \mathrm{~ms}$ (prolonged) (CPMP/986/96 1997). The missing ECGs were mainly due to temporary technical problems with ECG recording. The index date was the date of the ECG at baseline and the same date, blood samples were collected.

\section{Covariates}

Diabetes mellitus, hypertension, myocardial infarction, and heart failure are considered to be risk factors for QTc prolongation and the presence of these conditions at each index date was included as a covariate (Davey et al. 2000, Brown et al. 2001, Gaudron et al. 2001, Passino et al. 2004). Clinical measures were obtained during the visits at the Rotterdam Study research center. Diabetes mellitus and hypertension were 
2000 Subjects (random selection of the Rotterdam Study)

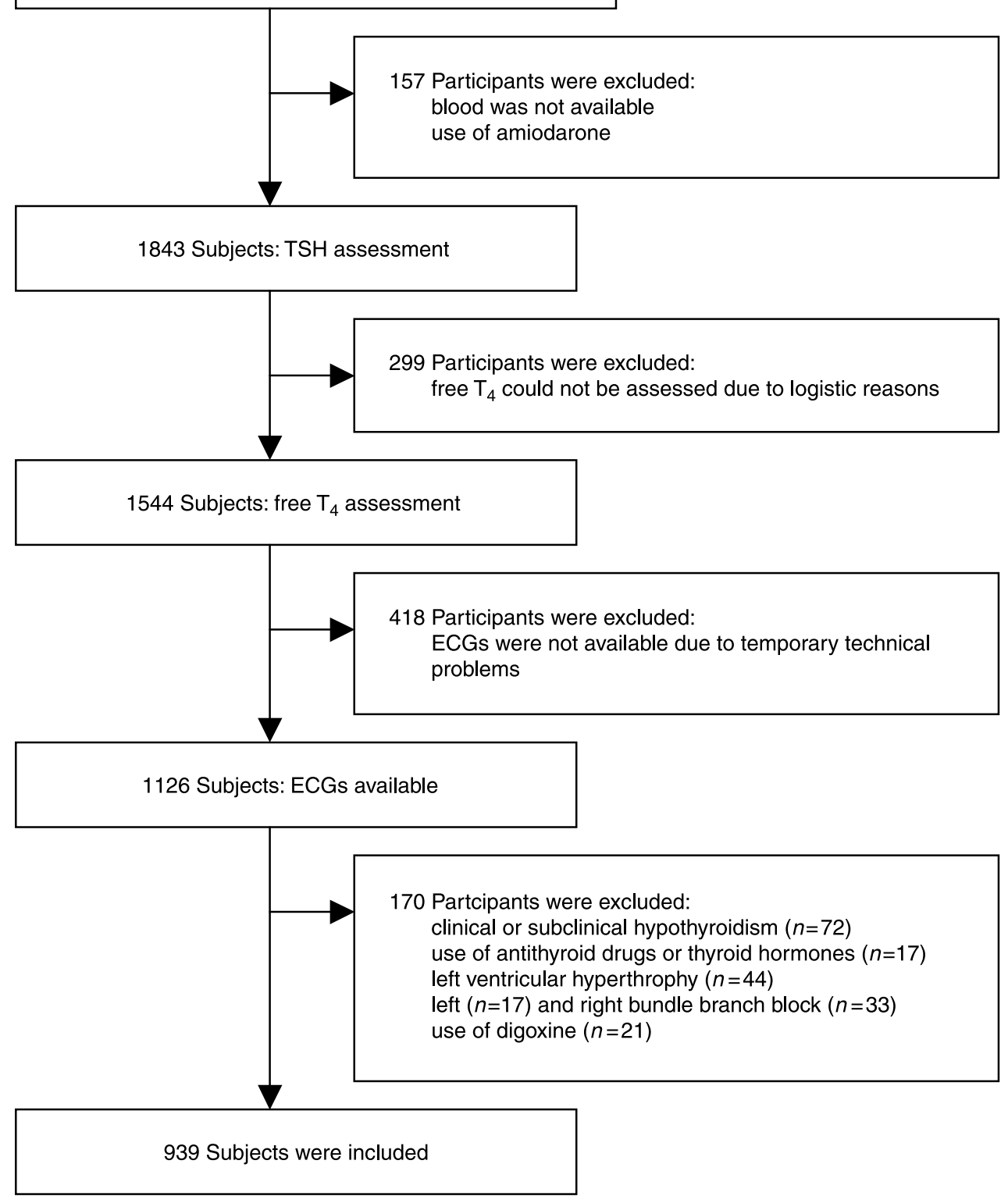

Figure 1 Diagram of study population.

defined according to the World Health Organization (WHO Diabetes mellitus 1985, WHO 1999) criteria. The prevalence of myocardial infarction was assessed by hospital discharge diagnosis or in case a patient was not hospitalized, when signs and symptoms were reports, analysis of the standard 12-lead ECG and cardiac enzyme data were diagnostic of a myocardial infarction (Bots et al. 1997, Vliegenthart et al. 2002). The prevalence of heart failure was assessed by the presence of suggestive signs and symptoms as described previously (Mosterd et al. 1999, Bleumink et al. 2004).

\section{Statistical analysis}

Two analyses were conducted. First, a linear regression analysis was conducted with QTc as outcome and thyroid status (TSH and free $\mathrm{T}_{4}$ levels divided in quintiles) as determinants. Secondly, logistic regression analysis was conducted to assess the risk of a borderline QTc interval or QTc prolongation. All analyses were adjusted for age and gender and additionally for diabetes mellitus, myocardial infarction, hypertension, and heart failure. In a separate analysis, we have examined the 
association between TSH and QTc prolongation using log TSH, since TSH is logarithmically distributed.

Because women in general have a longer QTc interval than men, a separate analysis was conducted with stratification for gender. In a separate analysis, we also adjusted for potassium, calcium, and the use of class 1 QTc-prolonging drugs of list 1 of the website-based registry (http:www.qtdrugs.org/ medicalpros/drug-lists.htm) at the index date, since these drugs are generally accepted to have a risk of causing Torsade de Pointes. Furthermore, we have performed a sensitivity analysis by excluding participants with clinical or subclinical hyperthyroidism.

All analyses were performed using SPSS for Windows version 11.0 (Chicago, IL, USA).

\section{Results}

\section{Subject characteristics}

The baseline characteristics of the participants are presented in Table 1. Overall, 939 participants were included, of whom 574 were females and 365 were males. The mean age of the study population at baseline was $68 \cdot 0$ years (S.D. $=7 \cdot 6$ years). Women were significantly older than men. Mean TSH at baseline was $1.60 \mathrm{mU} / 1 \quad($ s.D. $=0.90)$, mean free $\mathrm{T}_{4}$ was $16 \cdot 5 \mathrm{pmol} / \mathrm{l}$ (S.D. $=3 \cdot 0)$. Ten participants had clinical hyperthyroidism and 49 participants had subclinical hyperthyroidism.

\section{QTc prolongation}

The mean duration of the QTc interval at baseline was significantly shorter in males $(424.0 \mathrm{~ms})$ than in females (432.9 ms; $P<0.0001)$. Overall, $73.6 \%$ of the participants had normal QTc duration and $20 \cdot 4 \%$ had a borderline QTc interval, using the above-mentioned gender-specific cut-off points. Furthermore, 56 participants had QTc prolongation, with mean QTc levels of $473 \cdot 7 \mathrm{~ms}$.

Overall, there was no significant association between TSH and QTc interval with a decrease of $0.6 \mathrm{~ms}(95 \% \mathrm{CI}-2 \cdot 1$, $0 \cdot 9)$ per $\mathrm{mU} / 1$. The first quintile of TSH was not associated with an increase in the QTc interval $(0 \cdot 8 \mathrm{~ms}(95 \% \mathrm{CI}-3 \cdot 5$, $5 \cdot 2)$ ) compared with the fifth quintile. This effect fluctuated among the other quintiles. TSH was not associated with the risk of borderline QTc interval or QTc prolongation (Table 2). Additional analyses using log TSH did not change the results.

By contrast, there was a significant age- and genderadjusted association between free $\mathrm{T}_{4}$ levels and QTc interval with an increase of $0.6 \mathrm{~ms}(95 \% \mathrm{CI} 0 \cdot 1,1 \cdot 0)$ per $\mathrm{pmol} / 1$. The highest quintile of free $\mathrm{T}_{4}$ was not associated with an increase in the QTc interval $(3.2 \mathrm{~ms}(95 \% \mathrm{CI}-1 \cdot 1,7 \cdot 6))$ in comparison with the first quintile. The $P$ value for linear trend was 0.031 with a gradual increase in the QTc interval among the quintiles. The fifth quintile of free $T_{4}$ was associated with a significantly higher risk of a borderline QTc interval or QTc prolongation (odds ratio (OR) 1.72 (95\% CI $1 \cdot 07,2 \cdot 77)$ ) compared with the lowest quintile (Fig. 2). The $P$ value for linear trend was $0 \cdot 003$. After adjustment for diabetes mellitus, hypertension, myocardial infarction, and heart failure, the results changed minimally.

\section{Stratified analysis for gender}

After stratification by gender, the effects were significant in men but not in women (Table 3). The fifth quintile of free $T_{4}$ was associated with a significant age-adjusted increase in the QTc interval of $10.9 \mathrm{~ms}(95 \% \mathrm{CI} 3.4,18 \cdot 3)$ in men, with a significant linear trend $(P=0 \cdot 004)$. The fifth quintile of free $\mathrm{T}_{4}$ was associated with a significantly increased risk of a borderline QTc interval in men (OR 2.40 (95\% CI 1·20, $4 \cdot 80)$ with a gradual increase $(P$ value for linear trend was

Table 1 Baseline characteristics

\begin{tabular}{|c|c|c|c|}
\hline & Total & (Sub)clinical hyperthyroidism & No hyperthyroidism \\
\hline Number of participants & 939 & 59 & 880 \\
\hline Age (years, mean, (s.D.)) & $68 \cdot 0(7 \cdot 6)$ & $67 \cdot 9(7 \cdot 4)$ & $68 \cdot 0(7 \cdot 6)$ \\
\hline Mean QTc interval (ms) (s.D.) & $429 \cdot 4(21 \cdot 7)$ & $429 \cdot 3(23 \cdot 4)$ & $429 \cdot 4(21 \cdot 6)$ \\
\hline Borderline QTc prolongation $(n,(\%))$ & $192(20 \cdot 4 \%)$ & $14(23 \cdot 7 \%)$ & $178(20 \cdot 2 \%)$ \\
\hline Abnormal QTC prolongation $(n,(\%))$ & $56(6 \cdot 0 \%)$ & $1(1 \cdot 7 \%)$ & $55(6 \cdot 3 \%)$ \\
\hline Myocardial infarction $(n,(\%))$ & $101(10 \cdot 8 \%)$ & $1(1 \cdot 7 \%)^{*}$ & $100(11 \cdot 4 \%)^{*}$ \\
\hline Hypertension $(n,(\%))$ & $282(30 \cdot 0 \%)$ & $17(28 \cdot 8 \%)$ & $265(30 \cdot 1 \%)$ \\
\hline Heart failure $(n,(\%))$ & $9(1 \cdot 0 \%)$ & $1(1 \cdot 7 \%)$ & $8(0 \cdot 1 \%)$ \\
\hline Use of $\beta$-blocking drugs $(n,(\%))$ & $12(1 \cdot 3 \%)$ & 0 & $12(1 \cdot 4 \%)$ \\
\hline Use of QTc-prolonging drugs $(n,(\%))$ & $13(1 \cdot 4 \%)$ & $1(1 \cdot 7 \%)$ & $12(1 \cdot 4 \%)$ \\
\hline Mean TSH (mU/l) (S.D.) & $1 \cdot 60(0 \cdot 90)$ & $0 \cdot 29(0 \cdot 36)^{*}$ & $1 \cdot 69(0 \cdot 86)^{*}$ \\
\hline Mean free $\mathrm{T}_{4}(\mathrm{pmol} / \mathrm{l})$ (s.D.) & $16 \cdot 5(3 \cdot 0)$ & $19 \cdot 8(5 \cdot 0)^{*}$ & $16 \cdot 3(2 \cdot 6)^{*}$ \\
\hline
\end{tabular}

S.D., standard deviation; *P<0.05; the use of $\beta$-blocking drugs and QTc-prolonging drugs was defined as use at the index date. 
Table 2 Association of thyroid status with QTc interval

\begin{tabular}{|c|c|c|c|c|}
\hline & $\begin{array}{l}\text { QTc prolongation in } \\
\text { ms }(95 \% \mathrm{Cl})^{\mathrm{a}}\end{array}$ & $\begin{array}{l}\text { QTc prolongation in } \\
\text { ms }(95 \% \mathrm{Cl})^{\mathrm{b}}\end{array}$ & $\begin{array}{l}\text { or abnormal QIC } \\
\text { prolongation } \\
(95 \% \mathrm{Cl})^{\mathrm{a}}\end{array}$ & $\begin{array}{l}\text { or abnormal QIC } \\
\text { prolongation } \\
(95 \% \mathrm{Cl})^{b}\end{array}$ \\
\hline \multicolumn{5}{|l|}{ TSH quintiles } \\
\hline$\leq 0.86$ & $0 \cdot 8(-3 \cdot 5,5 \cdot 2)$ & $0 \cdot 8(-3 \cdot 5,5 \cdot 1)$ & $1 \cdot 13(0 \cdot 70,1 \cdot 81)$ & $1 \cdot 13(0 \cdot 70,1 \cdot 83)$ \\
\hline $0 \cdot 87-1 \cdot 25$ & $2 \cdot 1(-2 \cdot 2,6 \cdot 4)$ & $1 \cdot 9(-2 \cdot 3,6 \cdot 2)$ & $1 \cdot 17(0.74,1 \cdot 88)$ & $1.16(0.72,1 \cdot 88)$ \\
\hline $1 \cdot 26-1 \cdot 66$ & $1 \cdot 0(-3 \cdot 3,5 \cdot 3)$ & $1 \cdot 1(-3 \cdot 2,5 \cdot 4)$ & $1.03(0.64,1.66)$ & $1.04(0.64,1.70)$ \\
\hline $1 \cdot 67-2 \cdot 31$ & $0 \cdot 5(-3 \cdot 8,4 \cdot 9)$ & $0 \cdot 6(-3 \cdot 7,4 \cdot 9)$ & $0.97(0.60,1.57)$ & $0.98(0.60,1.60)$ \\
\hline$\geq 2 \cdot 32$ & Reference & Reference & Reference & Reference \\
\hline $\bar{P}$ value for linear trend & $0 \cdot 514$ & $0 \cdot 857$ & $0 \cdot 424$ & $0 \cdot 448$ \\
\hline \multicolumn{5}{|l|}{ Free $\mathrm{T}_{4}$ quintiles } \\
\hline$\leq 13.9$ & Reference & Reference & Reference & Reference \\
\hline$\overline{14} \cdot 0-15 \cdot 3$ & $-1 \cdot 2(-5 \cdot 6,3 \cdot 1)$ & $-1 \cdot 2(-5 \cdot 6,3 \cdot 1)$ & $0.93(0.56,1.54)$ & $0.93(0.56,1.55)$ \\
\hline $15 \cdot 4-16 \cdot 7$ & $0 \cdot 9(-3 \cdot 5,5 \cdot 3)$ & $1 \cdot 0(-3 \cdot 4,5 \cdot 3)$ & $1 \cdot 30(0 \cdot 79,2 \cdot 13)$ & $1.33(0.81,2 \cdot 19)$ \\
\hline $16 \cdot 8-18 \cdot 6$ & $2 \cdot 7(-1 \cdot 6,7 \cdot 1)$ & $2 \cdot 1(-2 \cdot 2,6 \cdot 4)$ & $1.56(0.97,2 \cdot 52)$ & $1.43(0.88,2 \cdot 34)$ \\
\hline$\geq 18 \cdot 7$ & $3 \cdot 2(-1 \cdot 1,7 \cdot 6)$ & $2 \cdot 6(-1 \cdot 7,6 \cdot 9)$ & $1 \cdot 72(1 \cdot 07,2 \cdot 77)^{*}$ & $1.59(0.98,2.58)$ \\
\hline$P$ value for linear trend & $0.031 *$ & 0.081 & $0.003 *$ & $0 \cdot 014^{*}$ \\
\hline
\end{tabular}

$\mathrm{Cl}$, confidence interval.

${ }^{a}$ Adjusted for age and gender; ${ }^{b}$ Adjusted for age, gender, diabetes, hypertension, myocardial infarction, and heart failure; TSH in $\mathrm{mU} / \mathrm{l}$ and free $\mathrm{T}_{4}$ in $\mathrm{pmol} / \mathrm{l}$; $* P<0 \cdot 05$.

0.003). In women, there was a non-significant trend towards a longer QTc interval in the highest quintiles of free $T_{4}$.

Additional adjustment for calcium, potassium, and use of class 1 QTc-prolonging drugs resulted in higher point estimates. The highest quintile of free $\mathrm{T}_{4}$ in males was associated with a significant adjusted increase in the QTc interval of $12.7 \mathrm{~ms}(95 \%$ CI $5 \cdot 6,19 \cdot 9)$ with a gradual increase $(P$ value for linear trend was $<0 \cdot 0001)$. The fifth quintile of free $T_{4}$ in males was associated with a significantly higher risk of a borderline QTc interval or QTc prolongation (OR 3.29 $(95 \%$ CI $1.50,7 \cdot 22)$ ) compared with the first quintile. The $P$ value for linear trend was $0 \cdot 001$.

Exclusion of the 59 participants with clinical or subclinical hyperthyroidism did not change the results substantially. The highest quintile of free $\mathrm{T}_{4}$ in males was associated with a significant adjusted increase in the QTc interval of $9.7 \mathrm{~ms}$ $(95 \%$ CI $2 \cdot 1,17 \cdot 2)$ with a gradual increase $(P$ value for linear trend was $0 \cdot 008)$. The fifth quintile of free $T_{4}$ in males was associated with a significantly higher risk of a borderline QTc interval or QTc prolongation (OR $2 \cdot 12$ (95\% CI 1·02, 4·40)) compared with the first quintile. The $P$ value for linear trend was $0 \cdot 009$.

\section{Discussion}

In this population-based study, we found an association between free $T_{4}$ levels and prolongation of the QTc interval. As far as we know, this is the first time that this was demonstrated in a large cohort study of an elderly population. The QTc interval increases gradually among the quintiles and the prolongation appears to be strongest in men with a prolongation of $\sim 10 \mathrm{~ms}$ in the highest quintile. Even after exclusion of participants with hyperthyroidism, free $\mathrm{T}_{4}$ levels are still associated with prolongation of the QTc interval. We did not find an association between TSH and QTc interval. A potential explanation for this finding is that an association between TSH and QTc would be indirect, while free $\mathrm{T}_{4}$ is more directly related to thyroid hormone action on the heart. $\mathrm{TSH}$ binds to the TSH receptor on thyroid cells, resulting in stimulation of thyroid hormone production but has probably not an effect on QTc of its own (Volpe 1997).

Thyroid hormone may affect ventricular repolarization but the literature differs with respect to the direction of this alteration. Hypothyroidism has been associated with prolongation of the QTc interval (Sarma et al. 1990, Fazio et al. 1992). The mechanism behind this association might be an

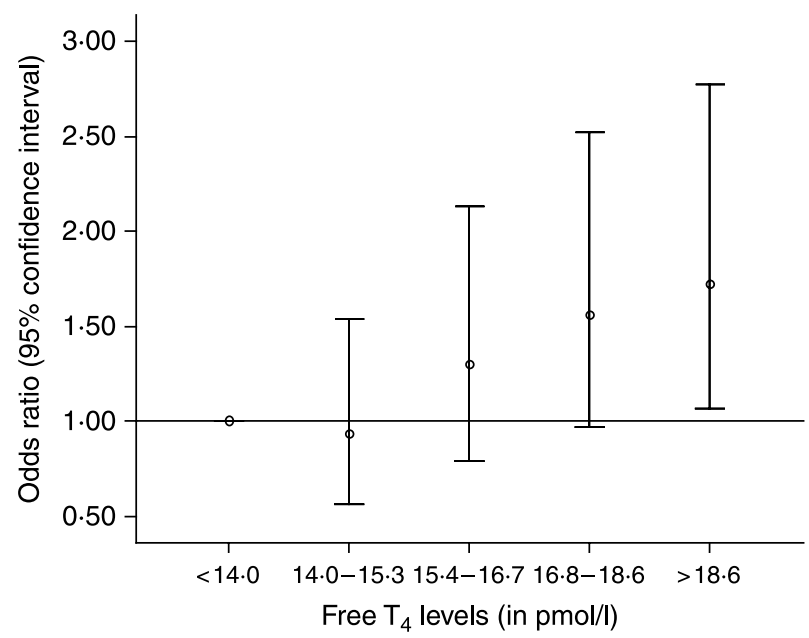

Figure 2 Differences between the risks of borderline or abnormal QTc prolongation in the free $\mathrm{T}_{4}$ quintiles compared with the lowest quintile. 
Table 3 Association of free thyroxine $\left(\mathrm{T}_{4}\right)$ with QTc interval stratified for men and women

\begin{tabular}{|c|c|c|c|c|}
\hline & $\begin{array}{l}\text { QTc prolongation } \\
\text { in } \mathbf{~} \mathbf{s}(95 \% \mathrm{Cl})^{\mathrm{a}}\end{array}$ & $\begin{array}{l}\text { QTc prolongation } \\
\text { in } \mathbf{~} \mathbf{s}(95 \% \mathrm{Cl})^{b}\end{array}$ & $\begin{array}{l}\text { Risk of borderline } \\
\text { or abnormal QTc } \\
\text { prolongation } \\
(95 \% \mathrm{Cl})^{\mathrm{a}}\end{array}$ & $\begin{array}{l}\text { Risk of borderline } \\
\text { or abnormal QTc } \\
\text { prolongation } \\
(95 \% \mathrm{Cl})^{b}\end{array}$ \\
\hline \multicolumn{5}{|l|}{ Free $\mathrm{T}_{4}$ quintiles male } \\
\hline$\leq 13 \cdot 8$ & Reference & Reference & Reference & Reference \\
\hline $13 \cdot 9-15 \cdot 1$ & $1 \cdot 5(-5 \cdot 9,8 \cdot 9)$ & $0 \cdot 6(-6 \cdot 8,7 \cdot 9)$ & $0.93(0.45,1.94)$ & $0.77(0.36,1 \cdot 65)$ \\
\hline $15 \cdot 2-16 \cdot 6$ & $6 \cdot 2(-1 \cdot 3,13 \cdot 7)$ & $6 \cdot 3(-1 \cdot 2,13 \cdot 7)$ & $1 \cdot 56(0 \cdot 77,3 \cdot 17)$ & $1 \cdot 63(0 \cdot 79,3 \cdot 37)$ \\
\hline$P$ value for linear trend & $0 \cdot 004^{*}$ & $0 \cdot 008^{*}$ & $0 \cdot 003 *$ & $0 \cdot 009 *$ \\
\hline \multicolumn{5}{|l|}{ Free $T_{4}$ quintiles female } \\
\hline$\leq 14 \cdot 1$ & Reference & Reference & Reference & Reference \\
\hline $14 \cdot 2-15 \cdot 5$ & $-1.9(-7 \cdot 3,3 \cdot 5)$ & $-2 \cdot 0(-7 \cdot 31,3 \cdot 4)$ & $1 \cdot 13(0 \cdot 56,2 \cdot 30)$ & $1 \cdot 11(0 \cdot 55,2 \cdot 27)$ \\
\hline $15 \cdot 6-16 \cdot 8$ & $-0 \cdot 8(-6 \cdot 0,4 \cdot 4)$ & $-1 \cdot 0(-6 \cdot 2,4 \cdot 2)$ & $1 \cdot 28(0 \cdot 65,2 \cdot 52)$ & $1 \cdot 29(0 \cdot 65,2 \cdot 55)$ \\
\hline $16 \cdot 9-18 \cdot 9$ & $-0 \cdot 6(-5 \cdot 9,4 \cdot 7)$ & $-0 \cdot 9(-6 \cdot 2,4 \cdot 4)$ & $1 \cdot 38(0 \cdot 70,2 \cdot 73)$ & $1 \cdot 34(0 \cdot 68,2 \cdot 66)$ \\
\hline
\end{tabular}

$\mathrm{Cl}$, confidence interval.

${ }^{\mathrm{a}}$ Adjusted for age; ${ }^{\mathrm{b}}$ Adjusted for age, diabetes, hypertension, myocardial infarction, and heart failure; free $\mathrm{T}_{4}$ in $\mathrm{pmol} / \mathrm{l} ;{ }^{*} P<0 \cdot 05$.

enhanced sympathetic activity (Colzani et al. 2001). Hyperthyroidism has been found to be associated with decreased as well as increased repolarization times. In animal studies (Johnson et al. 1973, Sharp et al. 1985, Binah et al. 1987, Gomberg-Maitland \& Frishman 1998) and in one human study (Dorr et al. 2006), decreased repolarization times have been found, however, in several small human studies (Linder 1955, Fisher 1982, Colzani et al. 2001, Owecki et al. 2006) and in an animal study (Johansson et al. 2002), QTc prolongation has been reported. In a prospective study comparing 16 patients with Graves' disease with a matched reference group, the 24-h average QTc in the Graves' patients was significantly prolonged and returned to normal after treatment of thyrotoxicosis. QTc has also been shown to be positively correlated with free tri-iodothyronine $\left(\mathrm{T}_{3}\right)$ and free $\mathrm{T}_{4}$ (Colzani et al. 2001).

A prospective study comparing patients with subclinical hyperthyroidism with healthy individuals, demonstrated that QTc intervals were significantly longer in patients with subclinical hyperthyroidism (Owecki et al. 2006). This prolongation might have clinical consequences since we demonstrated in earlier studies that QTc prolongation was associated with a threefold increased risk of sudden cardiac death (Straus et al. 2006). It is assumed, that even a minor average increase in the QTc interval in a population may enhance the risk of Torsade de Pointes in a small group of susceptible patients, if large numbers of patients are exposed. Some QTc-prolonging drugs, which were withdrawn from the market because of Torsade de Pointes, were associated with a QTc interval prolongation of only 5-10 $\mathrm{ms}$ in patient populations (Roden 2004).

A possible explanation for the association of hyperthyroidism and QTc prolongation can be provided by an increase in the activity of cardiac $\mathrm{Na}^{+} / \mathrm{K}^{+}$ATPase due to thyroid hormone excess, leading to increased intracellular $\mathrm{K}^{+}$with subsequent membrane hyperpolarization (Polikar et al. 1993, Colzani et al. 2001). The effect appeared to be strongest in men. Women are known to have on average a longer QTc interval than men (CPMP/986/96 1997). The shorter QTc interval in men is attributed to the role of testosterone on the duration of the action potential, mainly due to enhancement of slowly activating delayed rectifier $\mathrm{K}^{+}$currents and suppression of L-type $\mathrm{Ca}^{2+}$ currents (Bai et al. 2005). In cardiomyocytes, sex hormone receptors influence the activity of cardiac $\mathrm{Na}^{+} / \mathrm{K}^{+}$ATPase. In hyperthyroid men, impaired sexual function, gynecomastia, asthenospermia, and low testicular volume are attributed to lowered bioavailable testosterone and a decreased free androgen index despite an increase in total and SHBG-bound testosterone (Abalovich et al. 1999, Zahringer et al. 2000). The decreased bioavailable testosterone level in hyperthyroid men results in less shortening of the QTc interval. Bioavailable testosterone decreases with age, and this could explain the relative QTc prolongation in men with high free $\mathrm{T}_{4}$ levels in this study of an elderly population (Gray et al. 1991, Ferrini \& Barrett-Connor 1998). Therefore, the difference in the QTc interval between male and female disappears in males with high free $\mathrm{T}_{4}$ levels.

Our study has several strengths. An advantage of the Rotterdam Study is its population-based character that decreases the risk of selection bias. The baseline characteristics of our subcohort were comparable with those of the whole population of the Rotterdam Study. Furthermore, the use of digital ECG recordings all measured using the MEANS system likely reduced intra- and interobserver variabilities in the assessment of the QTc interval. Confounding was minimized by adjusting for all known risk factors for QTc prolongation, although we cannot exclude the possibility of 
unknown confounders. However, our study has also some limitations. Because of the cross-sectional design, we cannot exclude that QTc prolongation was already present in some patients before the increase in free $T_{4}$. Therefore, the results from this study should be confirmed with longitudinal data from other large cohorts. Thyroid status was only assessed in a subgroup of the entire cohort of the Rotterdam Study. Validity is nevertheless unaffected since the selection was at random. Free $T_{3}$ measurements are not available in the Rotterdam Study, however, since $T_{4}$ is a prohormone of $T_{3}$ and $T_{3}$ exhibits greater activity, we expect that the results might have been more pronounced, if we would have used free $T_{3}$ as exposure. Finally, our study population consisted of participants aged 55 years and older, whether our findings can be generalized to other age groups requires further study.

In conclusion, we demonstrated in this cohort of an elderly population, that high levels of free $\mathrm{T}_{4}$ are associated with QTc prolongation in men. Although a QTc interval prolongation of $10 \mathrm{~ms}$ in one individual usually remains without clinical consequences, an average shift of $10 \mathrm{~ms}$ in a Gaussian distribution on a population level will inevitably push more individuals into the upper percentiles of the QTc interval with its increased risk of Torsade de Pointes and sudden cardiac death.

\section{Declaration of Interest}

M C J M S is an employee of Erasmus MC and hence has been involved as project leader and in analyses contracted by various pharmaceutical companies and received unconditional grants from Pfizer, Morck, Johnson \& Johnson, Amgen, Roche, GSK, Boehringer, Yamanouchi and Altana, none of which are related to the subject of this study. M C J M $\mathrm{S}$ has been consultant to Pfizer, Servier, Celgene, Novartis and Lundbeck on issues not related to this paper. All other authors have no conflict of interest that would prjudice its impartiality relevant to the research reported.

\section{Funding}

This research did not receive any specific grant from any funding agency in the public, commercial or not-for-profit sector.

\section{References}

Abalovich M, Levalle O, Hermes R, Scaglia H, Aranda C, Zylbersztein C, Oneto A, Aquilano D \& Gutierrez S 1999 Hypothalamic-pituitarytesticular axis and seminal parameters in hyperthyroid males. Thyroid 9 857-863.

Al-Khatib SM, LaPointe NM, Kramer JM \& Califf RM 2003 What clinicians should know about the QT interval. Journal of the American Medical Association 289 2120-2127.

Bai CX, Kurokawa J, Tamagawa M, Nakaya H \& Furukawa T 2005 Nontranscriptional regulation of cardiac repolarization currents by testosterone. Circulation 112 1701-1710.
Bazett HC 1920 The time relations of the blood-pressure changes after excision of the adrenal glands, with some observations on blood volume changes. Journal of Physiology 53 320-339.

van Bemmel JH, Kors JA \& van Herpen G 1990 Methodology of the modular ECG analysis system MEANS. Methods of Information in Medicine 29 346-353.

Binah O, Arieli R, Beck R, Rosen MR \& Palti Y 1987 Ventricular electrophysiological properties: is interspecies variability related to thyroid state? American Journal of Physiology 252 H1265-H1274.

Bleumink GS, Knetsch AM, Sturkenboom MC, Straus SM, Hofman A, Deckers JW, Witteman JC \& Stricker BH 2004 Quantifying the heart failure epidemic: prevalence, incidence rate, lifetime risk and prognosis of heart failure The Rotterdam Study. European Heart Journal 25 1614-1619.

Bots ML, Hoes AW, Koudstaal PJ, Hofman A \& Grobbee DE 1997 Common Carotid Intima-Media Thickness and Risk of Stroke and Myocardial Infarction: The Rotterdam Study. Circulation 96 1432-1437.

Brown DW, Giles WH, Greenlund KJ, Valdez R \& Croft JB 2001 Impaired fasting glucose, diabetes mellitus, and cardiovascular disease risk factors are associated with prolonged QTc duration. Results from the Third National Health and Nutrition Examination Survey. Journal of Cardiovascular Risk 8 227-233.

de Bruyne MC, Kors JA, Hoes AW, Kruijssen DA, Deckers JW, Grosfeld M, van Herpen G, Grobbee DE \& van Bemmel JH 1997 Diagnostic interpretation of electrocardiograms in population-based research: computer program research physicians, or cardiologists? Journal of Clinical Epidemiology 50 947-952.

Colzani RM, Emdin M, Conforti F, Passino C, Scarlattini M \& Iervasi G 2001 Hyperthyroidism is associated with lengthening of ventricular repolarization. Clinical Endocrinology 55 27-32.

CPMP/986/96 1997 The assessment of the potential for QT interval prolongation by non-cardiovascular medicinal products. London: Committee for proprietary medicinal products.

Darpo B, Agin M, Kazierad DJ, Layton G, Muirhead G, Gray P \& Jorkasky DK 2006 Man versus machine: is there an optimal method for QT measurements in thorough QT studies? Journal of Clinical Pharmacology 46 598-612.

Davey PP, Barlow C \& Hart G 2000 Prolongation of the QT interval in heart failure occurs at low but not at high heart rates. Clinical Science $\mathbf{9 8}$ 603-610.

Dorr M, Ruppert J, Robinson DM, Kors JA, Felix SB \& Volzke H 2006 The relation of thyroid function and ventricular repolarization: decreased serum thyrotropin levels are associated with short rate-adjusted QT intervals. Journal of Clinical Endocrinology and Metabolism 91 4938-4942.

Fazio S, Biondi B, Lupoli G, Cittadini A, Santomauro M, Tommaselli AP, Lombardi G \& Sacca L 1992 Evaluation, by noninvasive methods, of the effects of acute loss of thyroid hormones on the heart. Angiology $\mathbf{4 3}$ 287-293.

Ferrini RL \& Barrett-Connor E 1998 Sex hormones and age: a cross-sectional study of testosterone and estradiol and their bioavailable fractions in community-dwelling men. American Journal of Epidemiology 147 750-754.

Fisher J 1982 Thyrotoxic periodic paralysis with ventricular fibrillation. Archives of Internal Medicine 142 1362-1364.

Gaudron P, Kugler I, Hu K, Bauer W, Eilles C \& Ertl G 2001 Time course of cardiac structural, functional and electrical changes in asymptomatic patients after myocardial infarction: their inter-relation and prognostic impact. Journal of the American College of Cardiology 38 33-40.

Gomberg-Maitland M \& Frishman WH 1998 Thyroid hormone and cardiovascular disease. American Heart Journal 135 187-196.

Gray A, Berlin JA, McKinlay JB \& Longcope C 1991 An examination of research design effects on the association of testosterone and male aging: results of a meta-analysis. Journal of Clinical Epidemiology 44 671-684.

Harjai KJ \& Licata AA 1997 Effects of amiodarone on thyroid function. Annals of Internal Medicine 126 63-73.

Hofman A, Grobbee DE, de Jong PT \& van den Ouweland FA 1991 Determinants of disease and disability in the elderly: the Rotterdam Elderly Study. European Journal of Epidemiology 7 403-422. 
Hofman A, Breteler MM, van Duijn CM, Krestin GP, Pols HA, Stricker BH, Tiemeier H, Uitterlinden AG, Vingerling JR \& Witteman JC 2007 The Rotterdam Study: objectives and design update. European Journal of Epidemiology 22 819-829.

Johansson C, Koopmann R, Vennstrom B \& Benndorf K 2002 Accelerated inactivation of voltage-dependent $\mathrm{K}^{+}$outward current in cardiomyocytes from thyroid hormone receptor alpha1-deficient mice. Journal of Cardiovascular Electrophysiology 13 44-50.

Johnson PN, Freedberg AS \& Marshall JM 1973 Action of thyroid hormone on the transmembrane potentials from sinoatrial node cells and atrial muscle cells in isolated atria of rabbits. Cardiology 58 273-289.

Kalmijn S, Mehta KM, Pols HA, Hofman A, Drexhage HA \& Breteler MM 2000 Subclinical hyperthyroidism and the risk of dementia. The Rotterdam study. Clinical Endocrinology 53 733-737.

Kulan K, Ural D, Komsuoglu B, Agacdiken A, Goldeli O \& Komsuoglu SS 1998 Significance of QTc prolongation on ventricular arrhythmias in patients with left ventricular hypertrophy secondary to essential hypertension. Internal Journal of Cardiology 64 179-184.

Lasser KE, Allen PD, Woolhandler SJ, Himmelstein DU, Wolfe SM \& Bor DH 2002 Timing of new black box warnings and withdrawals for prescription medications. Journal of the American Medical Association 287 2215-2220.

Linder MA 1955 Periodic paralysis associated with hyperthyroidism: report of three cases. Annals of Internal Medicine 43 241-254.

Mosterd A, Hoes AW, de Bruyne MC, Deckers JW, Linker DT, Hofman A \& Grobbee DE 1999 Prevalence of heart failure and left ventricular dysfunction in the general population; The Rotterdam Study. European Heart Journal 20 447-455.

Owecki M, Michalak A, Nikisch E \& Sowinski J 2006 Prolonged ventricular repolarization measured by corrected QT interval (QTc) in subclinical hyperthyroidism. Hormone Metabolic Research 38 44-47.

Passino C, Franzoni F, Gabutti A, Poletti R, Galetta F \& Emdin M 2004 Abnormal ventricular repolarization in hypertensive patients: role of sympatho-vagal imbalance and left ventricular hypertrophy. Internal Journal of Cardiology 97 57-62.

Piotrowicz K, Zareba W, McNitt S \& Moss AJ 2007 Repolarization duration in patients with conduction disturbances after myocardial infarction. American Journal of Cardiology 99 163-168.

Polikar R, Burger AG, Scherrer U \& Nicod P 1993 The thyroid and the heart. Circulation 87 1435-1441.

Roden DM 2004 Drug-induced prolongation of the QT interval. New England Journal of Medicine 350 1013-1022.

Sarma JS, Venkataraman K, Nicod P, Polikar R, Smith J, Schoenbaum MP \& Singh BN 1990 Circadian rhythmicity of rate-normalized QT interval in hypothyroidism and its significance for development of class III antiarrhythmic agents. American Journal of Cardiology 66 959-963.
Sharp NA, Neel DS \& Parsons RL 1985 Influence of thyroid hormone levels on the electrical and mechanical properties of rabbit papillary muscle. Journal of Molecular and Cellular Cardiology 17 119-132.

Straus SM, Kors JA, De Bruin ML, van der Hooft CS, Hofman A, Heeringa J, Deckers JW, Kingma JH, Sturkenboom MC, Stricker BH et al. 2006 Prolonged QTc interval and risk of sudden cardiac death in a population of older adults. Journal of the American College of Cardiology 47 362-367.

Trantow T, Herzog R, Gegenheimer L \& Lucker PW 1994 A new method for the determination of the bioavailability of thyroid hormone preparations. Methods and Findings in Experimental and Clinical Pharmacology 16 133-140.

Vliegenthart R, Oudkerk M, Song B, van der Kuip DA, Hofman A \& Witteman JC 2002 Coronary calcification detected by electron-beam computed tomography and myocardial infarction. The Rotterdam Coronary Calcification Study. European Heart Journal 23 1596-1603.

Volpe R 1997 Rational use of thyroid function tests. Critical Reviews in Clinical Laboratory Sciences 34 405-438.

WHO 1999 World Health Organization-International Society of hypertension guidelines for the management of hypertension. Guidelines Subcommittee. Journal of Hypertension 17 151-183.

WHO Diabetes Mellitus 1985. Technical Reports series 894. Geneva: World Health Organisation.

Willems JL, Arnaud P, van Bemmel JH, Bourdillon PJ, Degani R, Denis B, Graham I, Harms FM, Macfarlane PW, Mazzocca G et al. 1987 A reference data base for multilead electrocardiographic computer measurement programs. Journal of the American College of Cardiology 10 1313-1321.

Willems JL, Abreu-Lima C, Arnaud P, van Bemmel JH, Brohet C, Degani R, Denis B, Gehring J, Graham I, van Herpen G et al. 1991 The diagnostic performance of computer programs for the interpretation of electrocardiograms. New England Journal of Medicine 325 1767-1773.

Yap YG \& Camm AJ 2003 Drug induced QT prolongation and torsades de pointes. Heart 89 1363-1372.

Zahringer S, Tomova A, von Werder K, Brabant G, Kumanov P \& Schopohl J 2000 The influence of hyperthyroidism on the hypothalamic-pituitarygonadal axis. Experimental and Clinical Endocrinology and Diabetes 108 $282-289$.

Received in final form 2 May 2008

Accepted 7 May 2008

Made available online as an Accepted Preprint

7 May 2008 